\title{
Allan B. Wolfson (Ed. in Ch.), Gregory W. Hendey, Louis J. Ling, Carlo L. Rosen, Jeffrey Schaider, Ghazala Q. Sharieff (Ass. Eds.): Harwood-Nuss' clinical practice of emergency medicine
}

\author{
Lippincott Williams\& Wilkins a Wolters Kluver Company, Philadelphia, Baltimore, \\ New York, London, Buenos Aires, Hong Kong, Sydney, Tokyo, Fifth Ed., 2010, 1752 pp., \\ 450 figures, Hardcover, 190,00 $€$, ISBN 978-0-7817-8943-1
}

\section{Pierre Kehr}

Received: 1 May 2010 / Accepted: 5 May 2010 / Published online: 19 May 2010

(C) Springer-Verlag 2010

Harwood-Nuss' Clinical Practice of Emergency Medicine is a concise and practical, yet comprehensive and accurate textbook that is aimed to serve the clinician, and to provide an educational resource for trainees and more experienced emergency medicine practitioners.

This Fifth Edition has been expanded and updated. The table of contents has been reorganized and new topics have been added.

Twenty five sections cover most of the subjects involved in emergency medicine: resuscitation, pain management, trauma, eye and dental emergencies, pulmonary, cardiac and vascular conditions, abdominal and gynecologic problems, neurological and psychiatric emergencies, dermatology, allergies and infection diseases, hematology, oncology and endocrinology, and finally pediatrics and toxicology.

The chapters are easy to read and accessible, and they provide a clinically focused and evidence-based summary of current emergency medicine practice. The presentation of each section is clear and didactic, with numerous highquality illustrations. The original feature of the book is the Common Pitfalls paragraph, and the Critical Intervention summary that comes at the end of each section.

To further streamline this edition and to make it available at any computer with Internet access, the entire text is available online. The Internet version includes not only the reference list from every chapter but also additional tables and figures.

Clinical Practice of Emergency Medicine is an outstanding reference for all the professionals involved in Emergency Care.

Dr. Claude Karger Strasbourg

No funds were received in support of this study.
P. Kehr $(\square)$

SOTEST, Strasbourg, France

e-mail: kehrpier@aol.com 